\title{
Very high cycle fatigue tests of quenched and self-tempered steel reinforcement bars
}

\author{
Marina Rocha • Silvain Michel • \\ Eugen Brühwiler • Alain Nussbaumer
}

Received: 28 August 2014/ Accepted: 21 March 2015/Published online: 27 March 2015

(C) RILEM 2015

\begin{abstract}
Investigations on the fatigue strength of steel reinforcement bars (rebars) mainly involves fatigue tests with hot rolled (HR) and cold worked (CW) steels. However, in the last few decades, HR and $\mathrm{CW}$ rebars were replaced by quenched and selftempered (QST) rebars with hardened surface layer. There still remains a lack of research on fatigue strength of QST rebars especially in the very high cycle domain i.e., number of stress cycles surpassing 5 million. This study is part of a further detailed investigation on the fatigue behaviour of $\mathrm{HR}, \mathrm{CW}$ and QST rebars in the very high cycle domain. It aims to investigate the fatigue performance of QST rebars axially tested at number of stress cycles in the range of $10^{6}-10^{8}$. A preliminary study of the gripping method is followed by fatigue test results including nondestructive inspection of the rebar surface and fractographic analyses. The rebar surface is examined with
\end{abstract}

M. Rocha $(\varangle) \cdot$ E. Brühwiler

Structural Maintenance and Safety Laboratory (MCS),

École Polytechnique Fédérale de Lausanne (EPFL),

Lausanne, Switzerland

e-mail: marina.rocha@alumni.epfl.ch

S. Michel

Mechanical Systems Engineering Laboratory, Swiss

Federal Laboratories for Materials Science and

Technology (EMPA), Dübendorf, Switzerland

\section{A. Nussbaumer}

Steel Structures Laboratory (ICOM), École Polytechnique

Fédérale de Lausanne (EPFL), Lausanne, Switzerland liquid penetrant to reveal fatigue crack location and size in specific frequency interval monitored during the tests. Fractured surface analyses are performed by scanning electron microscopy to detect the location from where fatigue cracks initiate. Cross sectional area reduction resulting from fatigue crack propagation is also determined. Fractographic investigations are compared with the fractured surfaces of $\mathrm{HR}, \mathrm{CW}$ and QST rebars from the literature.

Keywords Quenched and self-tempered rebars . High and very high cycle fatigue · Gripping method . Non-destructive inspection - Fractured surface analysis

\section{Introduction}

Reinforced concrete structures such as bridges are nowadays subjected to higher and more frequent traffic loads and thus they are more susceptible to fatigue damage. One of the key elements contributing to the bridge deck slab service life is the fatigue strength of steel reinforcement bars (rebars). Fatigue loading may lead to failure of rebars in the reinforced concrete without any sign of external structural distress except local concrete cracking.

Axial and bending tests of plain rebars and within concrete beams respectively are the two test methods commonly used to study the fatigue strength of rebars. Generally, fatigue tests on rebars are carried out as 
repetitive loading with stress ratio between 0 and 0.2 $[15,16,19]$. Axial fatigue tests on rebars are usually conducted on electromagnetic resonance machines at frequencies up to $150 \mathrm{~Hz}$ [9]. The disadvantage of these tests is related to the method of gripping the rebar. It tends to cause local stress concentration and premature failure of the rebar in the gripping area which are not characteristic of the rebar itself. Bending fatigue tests have the advantage of simulating the service conditions at the steel-concrete interface. However, concrete beams are usually tested by hydraulic machines at frequency smaller than $10 \mathrm{~Hz}$, with few tests conducted for number of cycles more than $10^{7}$, due to the high costs [15].

Fatigue tests carried out up to the 1980's were mainly on hot rolled (HR) and cold worked (CW) rebars. However, straight HR and CW rebars were replaced in most European countries by quenched and self-tempered (QST) rebars $[5,11]$. These rebars have a hard outer layer of martensite as a result of the specific QST treatment. This process known as Thermex or Tempcore has been introduced in Western Europe since 1974 [17].

Axial and bending fatigue tests performed on QST rebars have been reported in the literature. Thandavamoorthy [14] conducted fatigue tests with Tempcore rebars in eight concrete beams up to 2 million cycles; fatigue strength of QST rebars was found to be comparable to HR and CW rebars. In [19], Tempcore rebars survived to stress levels as high as $40 \%$ of the tensile strength $\sigma_{\mathrm{u}}$ and in some cases reached $60 \%$ up to 2 millions cycles. Surface imperfections and stress concentrations arising from the rib geometry were significant factors affecting the fatigue lifetime of the fractured rebars. Axial fatigue tests with Tempcore rebars were performed to a maximum of 5 million cycles [3]. The test results showed small scatter for rebars with different diameters. In [6], fatigue tests with HR, CW and Tempcore rebars were run to utmost 2 million cycles. Tempcore rebars showed considerably smaller scatter and higher fatigue strength than HR and CW rebars. In [13], concrete beams with embedded $12 \mathrm{~mm}$ diameter Thermex rebars were tested to utmost 10 million cycles. Rebars survived at stress levels higher than $40 \%$ of their yield strength $\sigma_{\mathrm{y}}$.

Fatigue tests performed on QST rebars are mostly limited to utmost 5 million cycles. Thus, fatigue resistance of QST rebars based on these test data can lead to incoherent resistance estimation in the very high cycle regime [4] i.e., beyond 5 million cycles. This paper presents an experimental investigation carried out on QST rebars in the very high cycle fatigue regime. The gripping arrangement used in the axial fatigue tests are discussed. The test frequency is monitored for fatigue crack detection using liquid penetrant testing. The fractured surfaces are analysed by scanning electron microscopy (SEM) and sites where fatigue cracks initiate are identified. Crack propagation region is estimated after test stopping.

\section{Material properties}

The chemical composition and mechanical properties of QST (Thermex) rebars with diameter of $16 \mathrm{~mm}$ were provided by the manufacturer and are summarised in Tables 1 and 2. These rebars come from two strand rollings and they were produced in the same day. The stress $\times$ strain curve for a QST rebar provided by the manufacturer is given in Fig. 1.

The microstructure consists of a hardened outer layer of martensite as indicated in Fig. 2 with a thickness of approximately $1.2 \mathrm{~mm}$ and a soft core of ferrite-pearlite. Vicker's hardness, measured in the cross section, varied from $265 \mathrm{HV}$ in the martensitic layer to $160 \mathrm{HV}$ in the core; these values are expected for QST rebars as given in $[11,19]$.

Table 1 Chemical composition of the QST rebar with diameter of $16 \mathrm{~mm}$

\begin{tabular}{ll}
\hline Elements & $\%$ \\
\hline $\mathrm{C}$ & 0.186 \\
$\mathrm{Si}$ & 0.22 \\
$\mathrm{Mn}$ & 0.86 \\
$\mathrm{P}$ & 0.023 \\
$\mathrm{~S}$ & 0.040 \\
$\mathrm{Cr}$ & 0.14 \\
$\mathrm{Mo}$ & 0.02 \\
$\mathrm{Ni}$ & 0.13 \\
$\mathrm{Cu}$ & 0.40 \\
$\mathrm{Sn}$ & 0.018 \\
$\mathrm{~V}$ & 0.002 \\
$\mathrm{Nb}$ & 0.002 \\
$\mathrm{Al}$ & 0.004 \\
$\mathrm{Ceq}$ & 0.398 \\
\hline
\end{tabular}

Ceq $(\%)=\mathrm{C}(\%)+$

$\frac{\mathrm{Mn}}{6}(\%)+\frac{\mathrm{Cr}+\mathrm{Mo}+\mathrm{V}}{5}(\%)+$

$\frac{\mathrm{Ni}+\mathrm{Cu}}{15}(\%)$
Ceq carbon equivalent
0.186

0.22

0.86

0.023

0.040

.14

.02

0.13

0.40

0.018

.002

002

0.398 
Table 2 Mechanical properties of the QST rebar with diameter of $16 \mathrm{~mm}$

\begin{tabular}{|c|c|c|c|c|c|}
\hline \multicolumn{2}{|c|}{$\sigma_{\mathrm{y}}(\mathrm{MPa})$} & \multicolumn{2}{|c|}{$\sigma_{\mathrm{u}}(\mathrm{MPa})$} & \multicolumn{2}{|c|}{$\varepsilon_{\mathrm{u}}(\%)$} \\
\hline M & SD & $\mathrm{M}$ & SD & $\mathrm{M}$ & SD \\
\hline 518 & 8.29 & 613 & 1.63 & 16.7 & 1.40 \\
\hline
\end{tabular}

$\sigma_{\mathrm{y}}$ yield strength, $\sigma_{\mathrm{u}}$ tensile strength, $\varepsilon_{\mathrm{u}}$ strain at maximum force, $M$ mean, $S D$ standard deviation

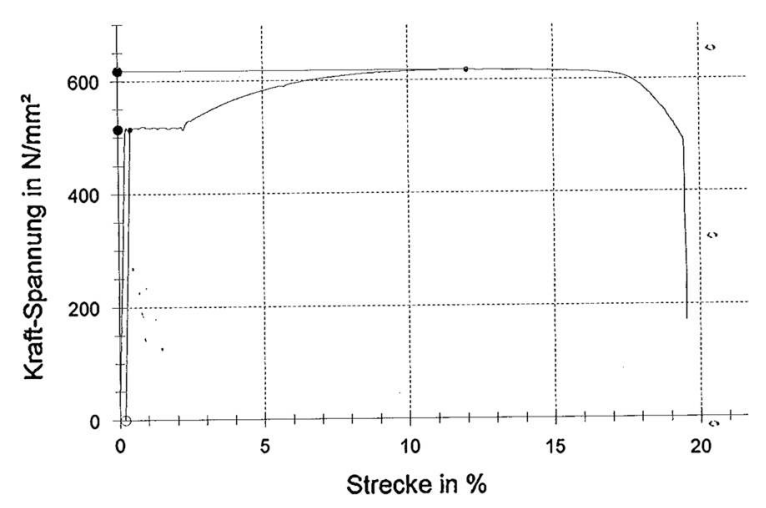

Fig. 1 Stress $\times$ strain curve of a QST rebar analysed in this study

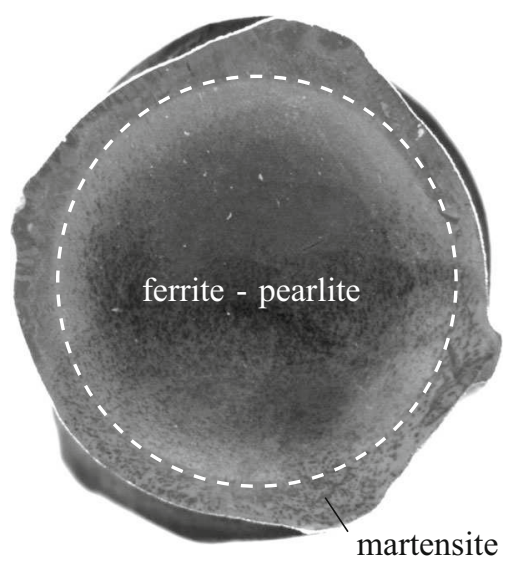

Fig. 2 Etched cross section of a $16 \mathrm{~mm}$ diameter QST rebar

\section{Test details}

\subsection{Grip arrangement and specimen preparation}

Axial fatigue tests are sensitive to the high stress concentration induced by the gripping pressure preventing the rebar from slipping. Some techniques were investigated to avoid premature failure of the rebar in the grip area.
The initial grip system used in the testing machine is shown in Fig. 3a. The grip has an inner-circular cross section of $20 \mathrm{~mm}$. Three types of gripping arrangement were used with the initial system in order to obtain the failure in the rebar free length: (1) A 1 $\mathrm{mm}$ aluminium sheet was wrapped around the rebar ends within the grip area with the aim to distribute the force evenly over the surface of the rebar as shown in Fig. 3b; (2) Shot peening the rebar ends (see Fig. 3c) to induce compressive residual stresses on the surface and (3) Welding and machining the rebar ends to create a gradual and smooth transition between the grips and the ribbed surface Fig. 3d. The cross section diameter of the welded and machined rebar ends was $20 \mathrm{~mm}$. However, all these methods were ineffective to prevent failure in the grip area.

Therefore, the initial grip system was replaced by a conical grip with maximum $18 \mathrm{~mm}$ diameter (see Fig. $4 a, b)$ in the testing machine. Conical grips have been mostly effective to prevent failure in the grip zone of axial fatigue tests performed on rebars to
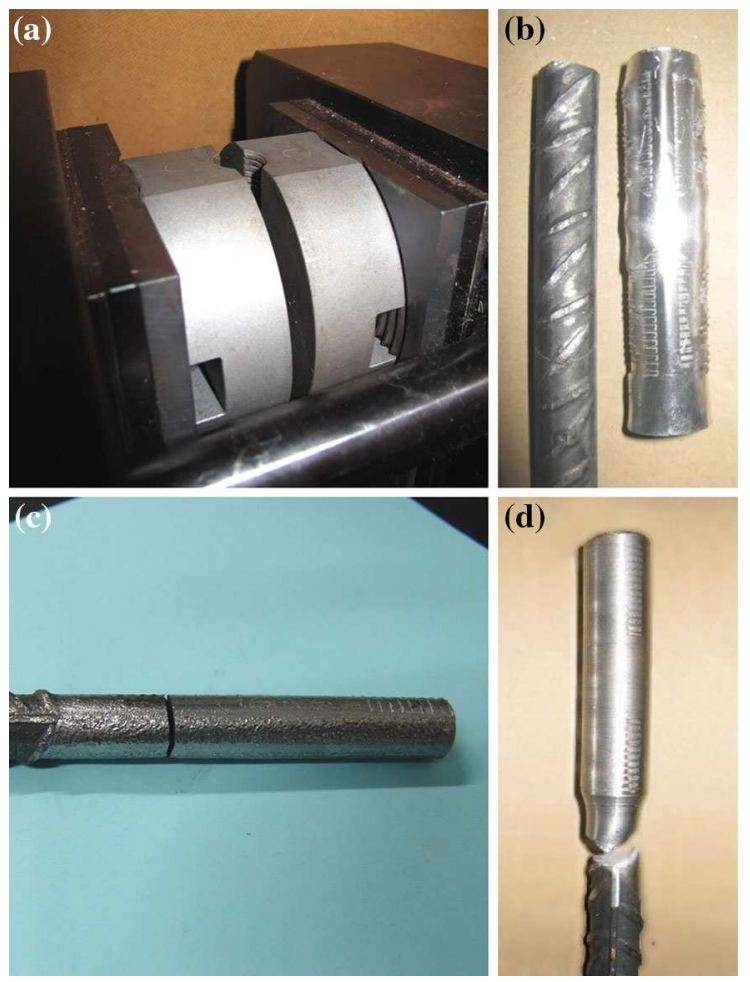

Fig. 3 a Initial grip system used for the fatigue tests. Rebar failure in the grip area with b Aluminium sheet; $\mathbf{c}$ Shot peened rebar ends; $\mathbf{d}$ Welded and machined rebar 
utmost 5 million cycles [3, 19]. These grips always required a preparation of the rebar ends: embedded rebar ends in Babbit metal (tin-lead alloy) within the conical grip and washers welded at each end. In [17], Babbit metal and high strength metallic grout surrounded the rebar within the conical grips, however, showed $40 \%$ of the failures in the grips and $60 \%$ within a distance of 1 diameter outside the grip area.

In the present study, three specimens were initially tested with the conical gripping system shown in Fig. 4a to verify its effectiveness. This grip was effective to prevent fatigue failure in the gripping area: failures occurred at least $39 \mathrm{~mm}$ away from the grip edges. This conical grip didn't require any preparation of the rebar ends.

The specimen preparation was as follows: $16 \mathrm{~mm}$ raw material was first examined for defects, scratches and manufacturer's identification marks. Then it was cut into pieces of $400 \mathrm{~mm}$ length. $80 \mathrm{~mm}$ on each side were necessary for clamping; therefore the free length was $240 \mathrm{~mm}$. The specimen free length considered in tests is in accordance with standard recommended procedures [8] where the rebar's free length in axial tests should be at least $140 \mathrm{~mm}$ or 14 times the specimen diameter, whichever is greater. Care was taken to ensure that the free length was free of manufacturer's identification marks. The rib patterns on both rebar sides are shown in Fig. 5a and b.

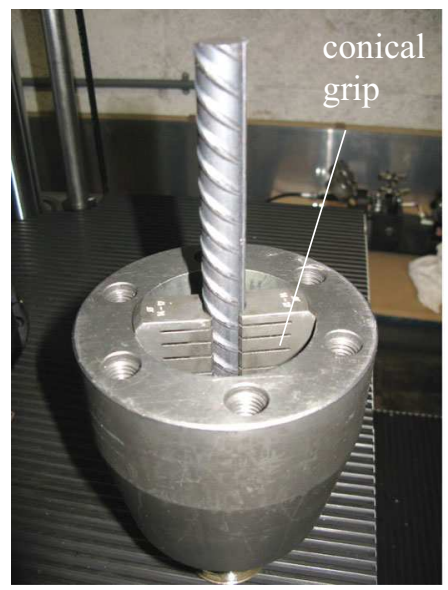

(a)

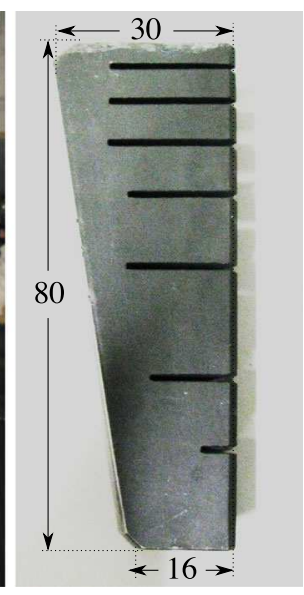

(b)
Fig. 4 a Conical grip system used for the fatigue tests; $\mathbf{b}$ detail of the conical grip

\subsection{Test method}

Axial fatigue tests were performed on a RUMUL Testonic $100 \mathrm{kN} 8601$ resonance machine at $85 \mathrm{~Hz}$ and force-ratio of 0.1 . A total of 21 specimens were tested; 6 tested specimens were considered as non-valid results since the failure occurred in the grip area. The valid tests i.e, rebars with failure in the free length were run to at least $1.89 \times 10^{6}$ cycles but not longer than $66.2 \times 10^{6}$ cycles as given in Table 3 . A modified staircase method was used to conduct the tests; the stress interval was determined based on the constant amplitude fatigue limit obtained from linear regression analysis of test results given in the literature [3, 19].

The failure within the rebar's free length occurred in more than $70 \%$ of the tested rebars. Whenever the specimen survived the test, it was termed "run-out". Two run-outs were retested under higher forces. It was assumed fatigue damage in the tested rebars for a surface crack length of at least $5 \mathrm{~mm}$. This is the minimum crack length that can be detected by the nondestructive inspection technique used in this work.

During all the tests that were carried out, the resonance frequency was monitored. The frequency change was used as an indication of cracking in the specimen. A typical evolution of the frequency drop obtained during the fatigue tests is shown in Fig. 6. The frequency drop versus number of cycles can be separated in three stages. In stage I, the frequency drops continuously from the beginning of the tests up to approximately $10^{6}$ cycles. The frequency drop in the beginning of the test was probably caused by the

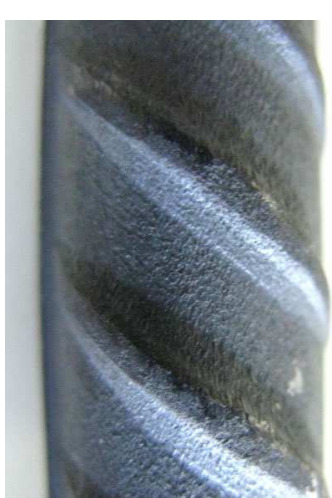

(a)

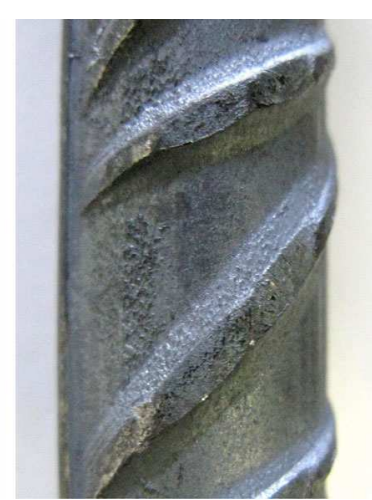

(b)
Fig. 5 Rib patterns at both sides of the tested QST rebars 
Table 3 Fatigue test results of $16 \mathrm{~mm}$ rebar
${ }^{\text {a }}$ Failure location: distance from the grip's edge to the failure in the free length

b Specimens 11 and 13 correspond to the retested 8 and 9 specimens at 251 and $255 \mathrm{MPa}$ respectively

\begin{tabular}{|c|c|c|c|c|}
\hline $\begin{array}{l}\text { Specimen } \\
\text { number }\end{array}$ & $\begin{array}{l}\text { Stress } \\
\text { range }(\mathrm{MPa})\end{array}$ & $\begin{array}{l}\text { Number of } \\
\text { cycles }\left(\times 10^{6}\right)\end{array}$ & $\begin{array}{l}\text { Failure (x) } \\
\text { Run-out (o) }\end{array}$ & Failure location $^{\mathrm{a}}(\mathrm{mm})$ \\
\hline 1 & 225 & 30 & o & - \\
\hline 2 & 235 & 30 & o & - \\
\hline 3 & 235 & 35 & o & - \\
\hline 4 & 243 & 36 & o & - \\
\hline 5 & 243 & 51 & o & - \\
\hline 6 & 243 & 49 & o & - \\
\hline 7 & 245 & 1.89 & $\mathrm{x}$ & 92 \\
\hline 8 & 247 & 30 & o & - \\
\hline 9 & 247 & 30 & o & - \\
\hline 10 & 247 & 30 & o & - \\
\hline $11^{\mathrm{b}}$ & 251 & 64.5 & o & - \\
\hline 12 & 251 & 66.2 & o & - \\
\hline $13^{\mathrm{b}}$ & 255 & 34.6 & o & - \\
\hline 14 & 255 & 2.71 & $\mathrm{x}$ & 60 \\
\hline 15 & 255 & 1.97 & $\mathrm{x}$ & 39 \\
\hline
\end{tabular}

settlement of the specimen in the clamping area. A stabilization of the frequency is observed at stage II with the frequency variation being smaller than $0.1 \%$. An abrupt frequency change occurs at stage III caused by fatigue crack propagation followed by failure of the specimen.

The test was interrupted just after the abrupt frequency change for non-destructive inspection by liquid penetrant for detection of fatigue cracks. The specimen remained mounted in the machine and

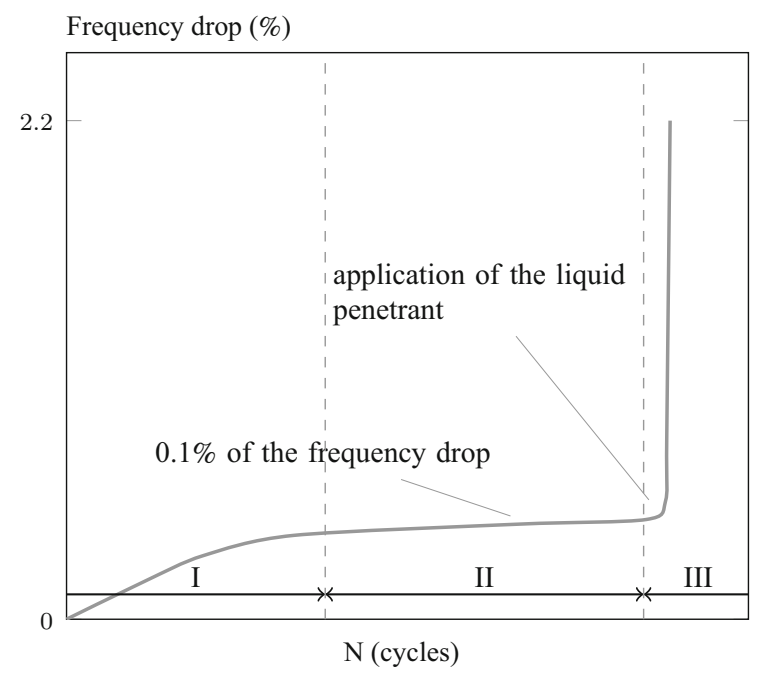

Fig. 6 Representative frequency drop (\%) of a failed specimen during the fatigue test loaded at the mean force while the liquid penetrant was applied on the surface. The liquid penetrant was applied only once. The test was stopped at a frequency drop of approximately $2.2 \%$.

\section{Results and discussions}

\subsection{Test results}

Table 3 shows the fatigue test results of the $16 \mathrm{~mm}$ rebars. Two specimens were retested at higher stresses after run-outs. The rebars were tested at stress ranges between 225 and $255 \mathrm{MPa}$ with two rebars being retested at higher stresses after run-outs. Three rebars showed a failure and all the others were run-outs. The failure location on the rebars are given in Table 3 . Run-outs represented $80 \%$ of the test results with one rebar surviving to a total of $94.5 \times 10^{6}$ cycles for a stress level of approximately $48 \%$ of the mean yield strength $\sigma_{\mathrm{y}}$.

Fatigue strength of rebars are traditionally expressed by $S-N$ curves. $S-N$ curves are obtained by linear regression applied only to failed data points; runouts are neglected in the analysis. In the standard $S$ $N$ curves, a minimum of 12 specimens is required for characteristic allowable and reliability data as given in [2]. The three failed specimens in this present work don't fit the minimum specimen size requirements for 
linear regression analysis. Therefore, the $S-N$ curve for the present test results couldn't be determined. In [4], an alternative approach is proposed for statistical treatment of the data including run-out specimens.

\subsection{Non-destructive inspection}

Non-destructive inspection allowed identifying the fatigue crack location and size on the surface of the failed specimens. The liquid penetrant was applied at the beginning of stage III as indicated in Fig. 6 .

The frequency change measured from the beginning of stage I until application of the liquid penetrant on the 3 failed specimens varied between 0.15 and $0.18 \%$. Figure 7 shows the frequency evolution obtained for the failed specimens 7, 14 and 15. Two dots of penetrant ink shown in Fig. 8a indicated the surface crack tips detected just after the abrupt frequency change in specimen 15 . The distance between the crack tips was approximately $8 \mathrm{~mm}$. Similar crack length was also detected on the surface of specimens 7 and 14. The crack propagated away from the non-uniform ribs and perpendicular to the longitudinal specimen axis. Figure $8 \mathrm{~b}$ shows the crack after the test stopping when the frequency dropped by $2.2 \%$. The crack area was approximately $50 \%$ of the specimen cross section.

The frequency drop versus number of cycles obtained for run-out specimens is given in Figs. 9, 10, 11 and 12. The frequency evolution of run-out specimens showed a similar tendency for stages I and II: A continuous frequency drop followed by an stabilization period until test stopping. The liquid penetrant was applied on the run-outs mounted in the machine at the end of the tests. However, no crack was detected on the surface of any surviving specimen, even for specimen 13 which showed a frequency drop of nearly $0.5 \%$.

\subsection{Fractured surface analyses}

Fractography analysis was performed by optical microscopy (OM) and XL30-FEG SEM in order to determine the location where fatigue cracks initiate. Since the tests were stopped before complete fracture of the specimens, it was required to split them and prepare the fractured surfaces before microscopic analysis. After test stopping, the specimen was put in liquid nitrogen in order to split them in a brittle manner

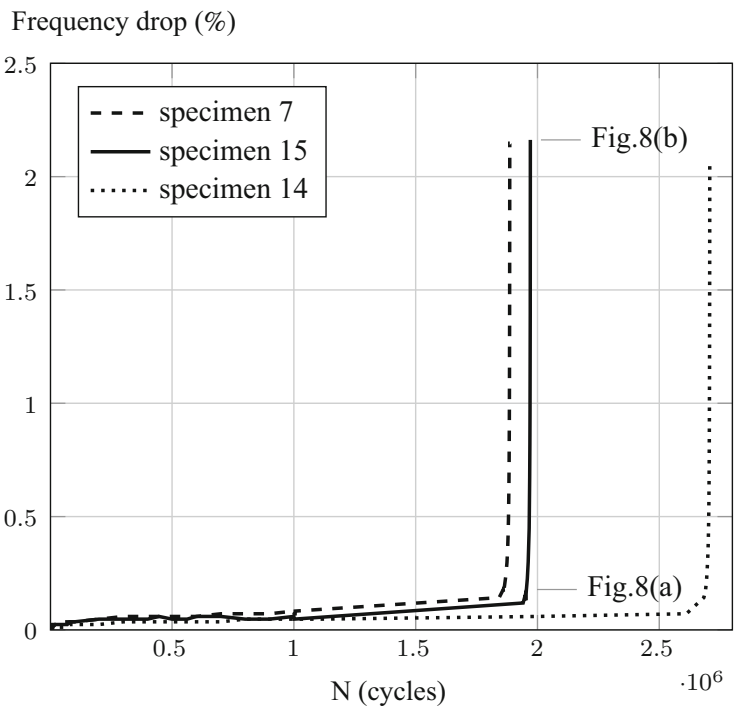

Fig. 7 Frequency drop versus number of cycles obtained for specimens 7, 14 and 15

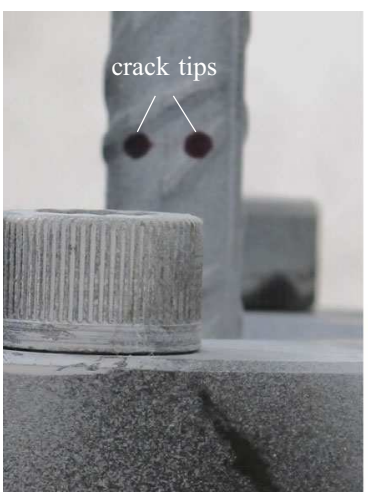

(a)

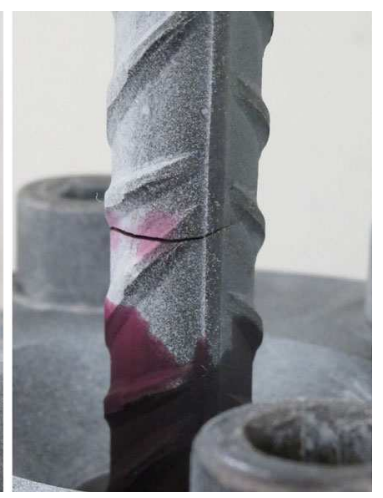

(b)
Fig. 8 a Specimen 15: two dots of penetrant ink indicating the fatigue crack tips on the specimen surface; b crack on the specimen surface when the test was stopped

using an actuator. The average temperature measured on the specimen surfaces was approximately $-65^{\circ} \mathrm{C}$ after 30 min immersed in liquid nitrogen. QST rebars tends to have a brittle fracture at this temperature [10]. The frozen specimen surfaces were dried using ethanol and compressed air and then left in desiccator under vacuum for one day. The fractured surfaces were then immersed in a beaker containing melted paraffin at $55{ }^{\circ} \mathrm{C}$ to protect them from damage. A cut was made at approximately $5 \mathrm{~cm}$ away from the fractured surfaces by Electric Discharge Machining. 


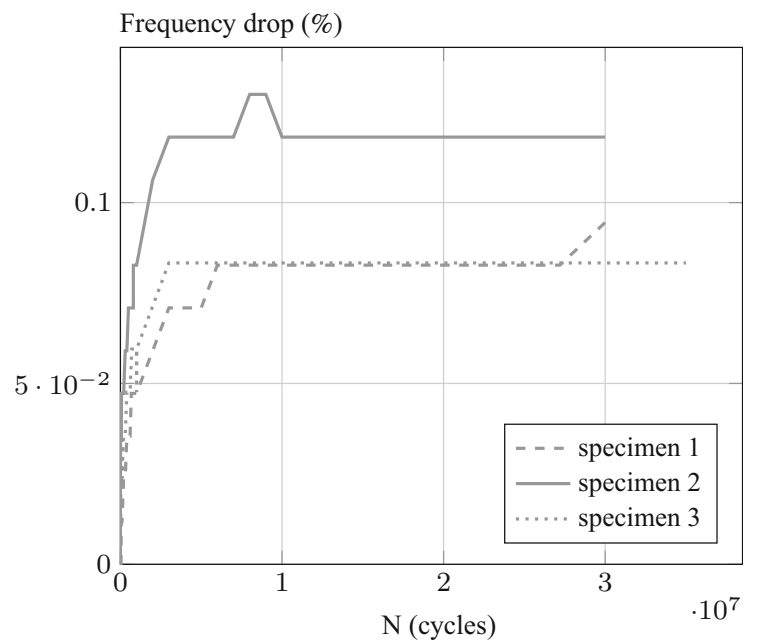

Fig. 9 Frequency drop versus number of cycles obtained for specimens 1,2 and 3

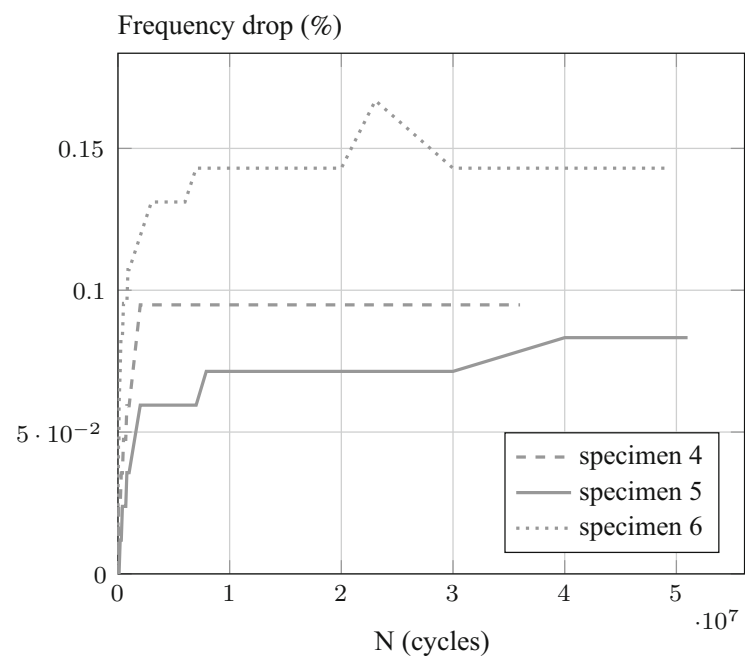

Fig. 10 Frequency drop versus number of cycles obtained for specimens 4,5 and 6

The paraffin around the specimen's cross section was manually removed. The cross sections were then immersed in an ultrasonic cleaner containing Xylene for 10 minutes in order to remove the residual paraffin. Since some corrosion was visible on the fractured surfaces, two methods of removing corrosion were used: 1) One side of the cross section was immersed in a beaker with Alconox solution heated up to $90{ }^{\circ} \mathrm{C}$ for 1 hour and 2) The other side was immersed in an ultrasonic cleaner for 10 s containing an acid solution, consisting of $3 \mathrm{~mL}$ of hydrochloric acid, $4 \mathrm{~mL}$ of

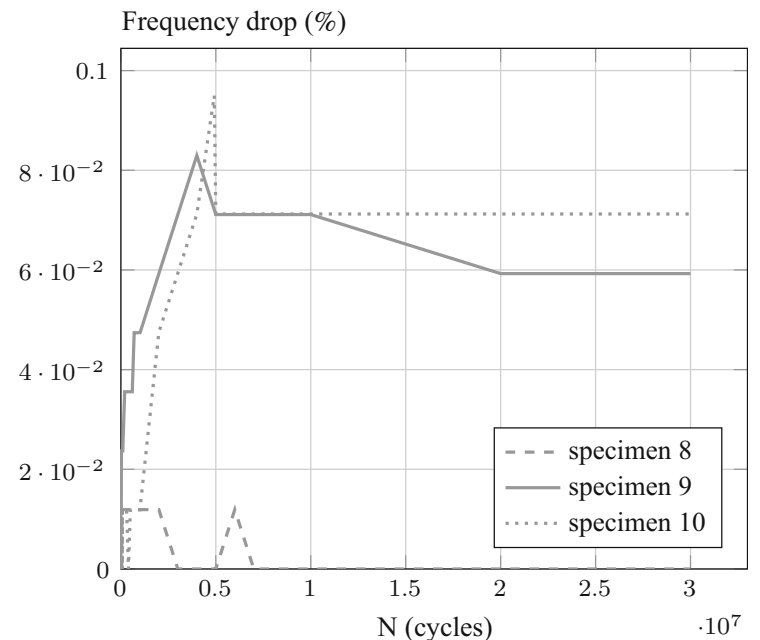

Fig. 11 Frequency drop versus number of cycles obtained for specimens 8,9 and 10

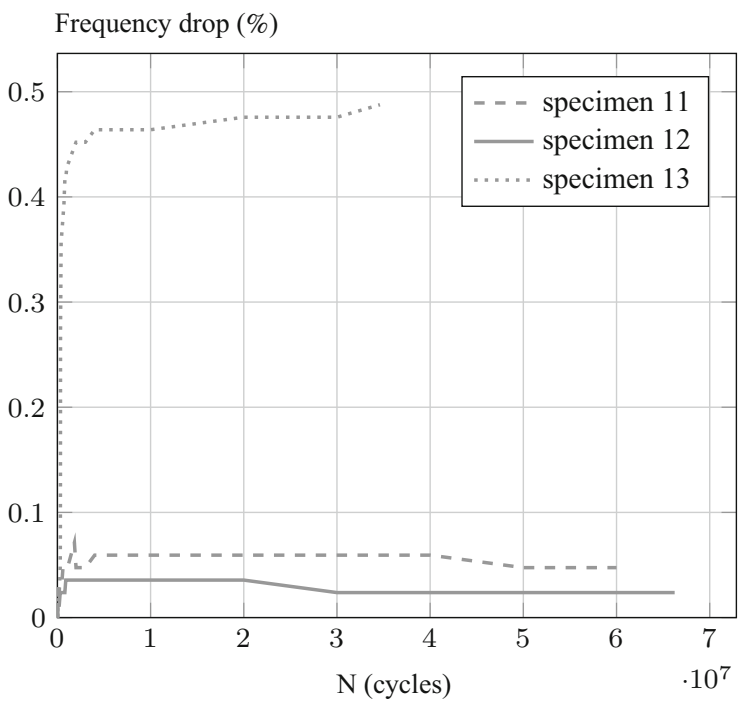

Fig. 12 Frequency drop versus number of cycles obtained for specimens 11,12 and 13

2-butyne-1, 4-diol (35\% aqueous solution) and $50 \mathrm{~mL}$ of deionized water [1]. Both methods were effective to remove the corrosion on the surface. After corrosion removal, the fractured surfaces were cleaned with ethanol, dried with compressed air and left in desiccator under vacuum to protect it from any damage before microscopic analysis.

The site from where fatigue cracks initiate on the specimen surface is indicated in Figs. 13a, 14a 
and $15 \mathrm{a}$. The crack initiated at or very near the base of the transverse non-uniform ribs. This behaviour is probably related to different surface imperfection on the two rebar faces; the peak values of the stress concentration factors determined at the base of uniform and non-uniform ribs are very close [12].

Figures 13b, 14b and 15b show the fatigue crack propagation region determined from fractography images obtained with OM. The bright rough area is the brittle fracture caused by the actuator whereas the smooth area is the fatigue crack region. The different surface texture allows determining the final fatigue crack area.

Imperfections on the fractured cross section from where fatigue cracks initiated are indicated in Figs. 13c, 14c and 15c. The cracks (white lines in the SEM images) emerging from the imperfections confirm the crack initiation site previously identified in the $\mathrm{OM}$ images. A single fatigue crack initiation site is identified on the cross sections of specimens 7 and 14: Cracks start to propagate from a imperfection size of approximately $1 \mathrm{~mm}$ and $0.8 \mathrm{~mm}$ in specimens 7 and 14 respectively as indicated in Fig. $13 \mathrm{c}$ and $14 \mathrm{c}$. In specimen 15 , fatigue cracks initiated from two imperfections on the cross section of approximately $0.3 \mathrm{~mm}$ and $0.45 \mathrm{~mm}$ as shown in Fig. 15c. Imperfections identified on the QST cross sections are originated from the manufacturing process.

Fractured surface analyses on HR, CW and QST rebars tested at high number of fatigue cycles have been reported in the literature [7, 9, 19]. According to [9], fatigue lifetime of $\mathrm{HR}$ and $\mathrm{CW}$ rebars axially tested at high number of cycles was mainly affected by surface defects ranging from 5 to $100 \mu \mathrm{m}$. HR rebars mostly had a single fatigue crack initiation site and plane fractured surface. CW rebars had multiple initiation sites and helical fractured surfaces.

In [19], fatigue cracks on QST rebars initiated from surface defects and at the root of the transverse ribs from where arise the highest stress concentration [18]. The plane fractured surface showed single or multiple initiation sites: Higher stress range and lower ratio between rib radius and rib height $r / h$ led to multiple initiation sites.

In [7], fatigue tests performed on HR rebars embedded in concrete beams resulted in fatigue cracks starting at the base of transverse ribs and plane fractured surface. The fractured surface of $\mathrm{CW}$ rebars embedded in concrete was plane inclined at an angle

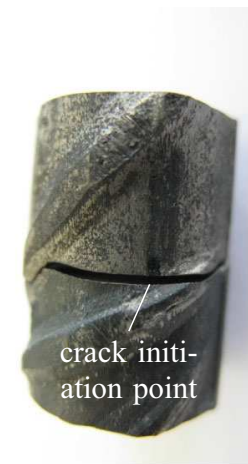

(a)

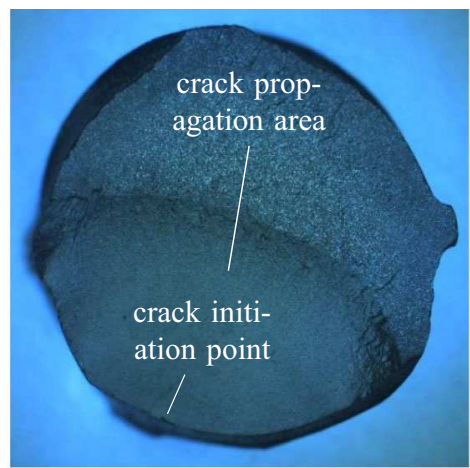

(b)

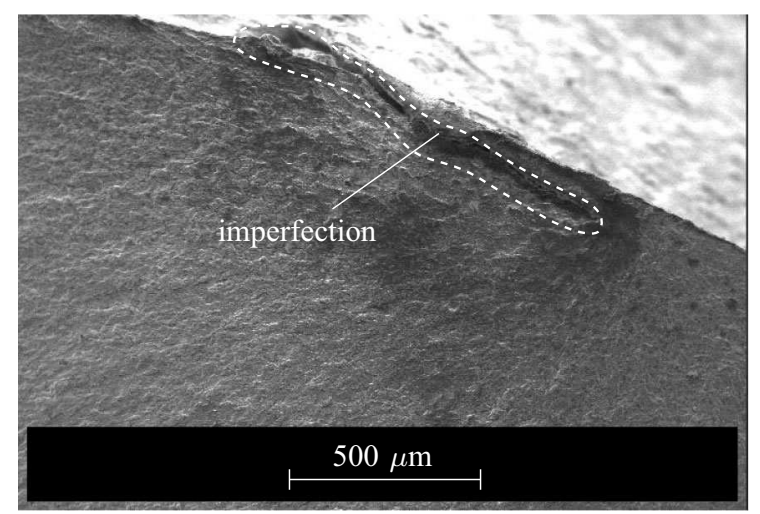

(c)

Fig. 13 a Location where fatigue crack initiates on the surface of specimen 7; b OM image $(\times 10)$ of the fractured cross section; c SEM image $(\times 65)$ of the imperfection from where fatigue crack initiated

of approximately $45^{\circ}$ and fatigue cracks initiated near to the transversal ribs.

Comparisons between the fractured surface investigations given in the literature [7, 9, 19] and the fractured surfaces analysed in this present work showed that fatigue life of HR, CW and QST was significantly affected by surface imperfections in axial fatigue tests at high cycle regime. In bending fatigue tests, the rib geometry had a significant effect on the fatigue lifetime of rebars. Beside, HR and QST rebars tested at high cycle fatigue tended to have a single crack initiation site and a similar plane fractured surface while $\mathrm{CW}$ rebars show a helical fractured surface.

\section{Conclusions}

Fatigue tests were performed on QST rebars between $10^{6}$ and $10^{8}$ cycles and under constant amplitude 


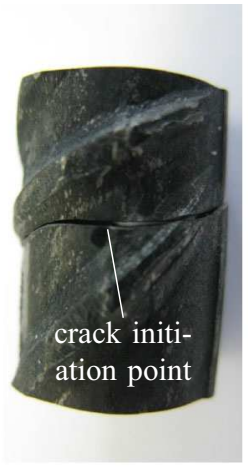

(a)

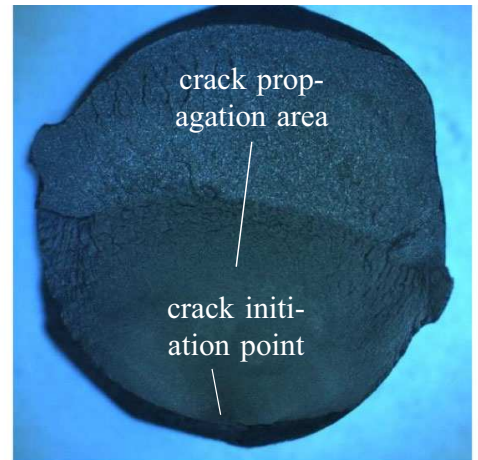

(b)

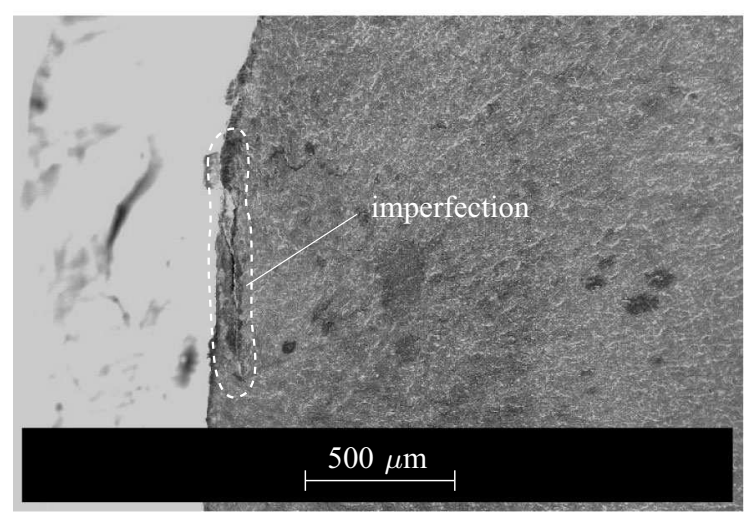

(c)
Fig. 14 a Location where fatigue crack initiates on the surface of specimen 14 ; b OM image $(\times 10)$ of the fractured cross section; c SEM image $(\times 65)$ of the imperfection from where fatigue crack initiated

loading. Non-destructive inspection using liquid penetrant allowed to determine the surface crack size and location just after the abrupt drop of the frequency. Fractured surfaces were analysed after test stopping by $\mathrm{OM}$ and SEM and compared to fractographic analysis from the literature. The following conclusions can be drawn from the present study:

- Conical grip arrangement was the only effective method to prevent failure in the grip area. The method provided more than $70 \%$ of the failures on rebar free length without requiring any modification at the rebar ends.

- QST rebars survived at least 30 million cycles in $80 \%$ of the tests and at stress levels of approximately $50 \%$ of the mean yield strength.

- Due to the small frequency change at almost the entire fatigue life of the rebars and the limitation of

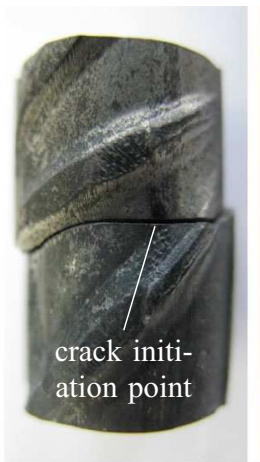

(a)

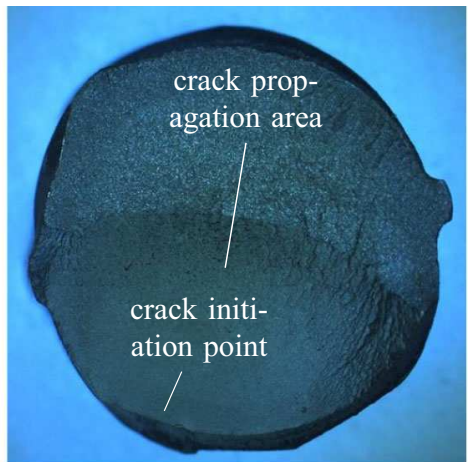

(b)

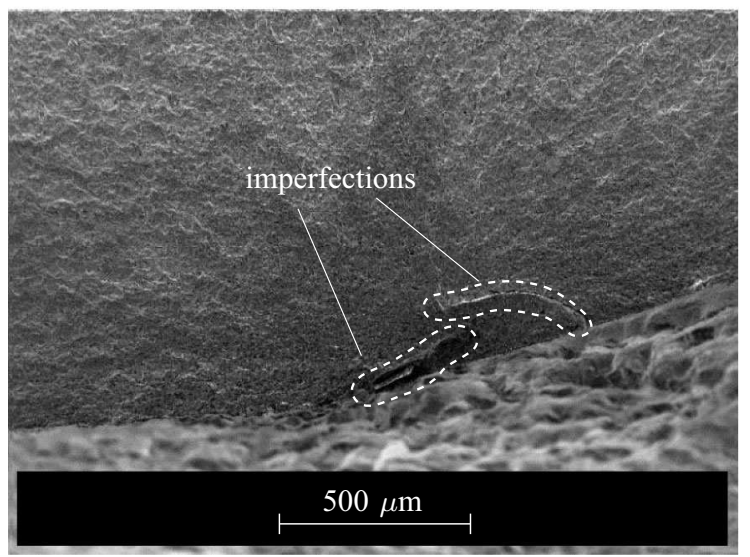

(c)

Fig. 15 a Location where fatigue crack initiates on the surface of specimen 15 ; b OM image $(\times 10)$ of the fractured cross section; c SEM image $(\times 65)$ of the imperfections from where fatigue crack initiated

the penetrant liquid testing in detect surface cracks from few $\mathrm{mm}$, fatigue cracks could only be detected when the rebar approached fracture.

- The fatigue lifetime of QST rebars was significantly controlled by manufacturing imperfections extending from surface to the depth cross section; fatigue cracks initiated from imperfections located at and very near the base of the transversal ribs.

Acknowledgments The authors are grateful to Danièle Laub from the Interdisciplinary Centre For Electron Microscopy (CIME) at EPFL for her advices and help with the sample preparation for the microscopic analyses. We are also grateful to Prof. Francesco Stellacci from the Supramolecular Nanomaterials and Interfaces Laboratory (SuNMIL) who provided the laboratory space for the preparation of the samples. 


\section{References}

1. ASM (1992) Handbook: Fractography. ASM International, New York

2. ASTM (2010) Standard practice for statistical analysis of linear or linearized stress-life (s-n) and strain-life $(\epsilon-n)$ fatigue data. E739-10 ASTM, West Conshohocken

3. Donnell M, Spencer W, Abel A (1986) Fatigue of tempcore reinforcing bars-the effect of galvanizing. In: Australasian conference on the mechanics of structures and materials, 10th, vol 2, Adelaide

4. D’Angelo L, Rocha M, Nussbaumer A, Brühwiler E (2014) S-n-p fatigue curves using maximum likelihood method for fatigue resistance curves with application to straight and welded rebars. EUROSTEEL, Naples

5. Economopoulos M, Respen Y, Lessel G, Steffs G (1975) Application of the tempcore process to the fabrication of high yield strength concrete-reinforcing bars. CRM Metall Rep 45:3-19

6. Fehlmann P (2012) Zur ermüdung von stahlbetonbrücken. $\mathrm{PhD}$ thesis, Diss., Eidgenössische Technische Hochschule ETH Zurich, Nr. 20231, 2012

7. Hanson JM, Burton KT, Hognestad E (1968) Fatigue tests of reinforcing bars-effect of deformation pattern. J PCA Res Dev Lab 10:2-13

8. ISO (2010) Steel for the reinforcement and prestressing of concrete-test methods-part 1: reinforcing bars, wire rod and wire. 15630-1 International Organization for Standardization, Geneva
9. Mallett GP (1991) Fatigue of reinforced concrete: state-ofthe-art review /2. HMSO, London

10. Nikolaou J, Papadimitriou GD (2005) Impact toughness of reinforcing steels produced by (i) the tempcore process and (ii) microalloying with vanadium. Int $\mathrm{J}$ Impact Eng 31(8):1065-1080

11. Rehm G, Russwurm D (1977) Assessment of concrete reinforcing bars made by the tempcore process. CRM Metall Rep 51:3-16

12. Rocha M, Brühwiler E, Nussbaumer A (2015) Geometrical and material characterisation of quenched and self-tempered steel reinforcement bars. J Mater Civil Eng, ASCE (under review)

13. Schläfli M (1999) Ermüdung von brückenfahrbahnplatten aus stahlbeton. PhD thesis, EPFL

14. Thandavamoorthy T (1999) Static and fatigue of highductility bars reinforced concrete beams. J Mater Civil Eng 11(1):41-50

15. Tilly G (1979) Fatigue of steel reinforcement bars in concrete: a review. Fatigue Fract Eng Mater Struct 2(3):251-268

16. Tilly G (1984) Fatigue testing and performance of steel reinforcement bars. Mater Constr 17(1):43-49

17. Virmani Y, Wright W, Nelson R (1991) Fatigue testing for thermex reinforcing bars. Public Roads 55(3)

18. Zheng H, Abel A (1998) Stress concentration and fatigue of profiled reinforcing steels. Int J Fatigue 20(10):767-773

19. Zheng H, Abel AA (1999) Fatigue properties of reinforcing steel produced by tempcore process. J Mater Civil Eng 11(2):158-165 